\title{
A Descriptive Study to Assess the Practice of Biomedical Waste Management among Staff Nurses at Base Hospital Kalmunai (North), Sri Lanka
}

\author{
Dr. R. Muraleeswaran
}

Medical Superintendent, Base Hospital Kalmunai North

\begin{abstract}
The aim and objective of the study was to assess the practice regarding biomedical waste management among staff nurses at Base hospital kalmunai (North),Sri Lanka. A descriptive study was adopted. A total of 60nurses participated in the present study, randomly chosen from various units. An observational checklist was used for data collection after getting their informed consent. Selfmade scoring system was used to categorize the participants as whether they follow the correct practice, partially correct practice or the incorrect practice. Purposive sampling technique was adopted to select the sample of the study. The result of the study concluded that the frequency and percentage distribution of level practice on biomedical waste management among staff nurses reveals that 34(56.66\%) staff nurses were found following correct practices, $14(23.33 \%)$ of staff nurses were found following partially correct practices, and 12(20\%) were following incorrect practices. The study reveals that some nurses were correctly practicing the various aspects of biomedical waste management but for some who were not found to be completely responsible for biomedical waste management in the hospital; their problems were sort out such as inadequate staff in the ward; less supervision, increase workloads, etc. It is the responsibility of the nurse to care for the environment and public health particularly in relation to the waste they produce. The importance of training regarding biomedical waste management cannot be overemphasized; lack of proper and complete knowledge about biomedical waste management impacts practices of appropriate waste disposal among staff nurses in the hospital.
\end{abstract}

Keywords: Nurse, biomedical waste, biomedical waste management, segregation, hospital

\section{Introduction}

All human activities and living thing on earth produce waste in some form or the other.persuasion of the aim of reducing health problems, eliminating potential risks, and treating sick people, healthcare services inevitably create waste which itself may be hazardous to health. The waste produced in the course of healthcare activities carries a higher potential for infection and injury than any other type of waste. Inadequate and inappropriate knowledge of handling of healthcare waste may have serious health consequences and a significant impact on the environment as well.In an age of wide spread global trade and technical development, new and existing diseases can cross national borders and threaten our collective security. Along with those factors hospital waste also has become threat to health.

Biomedical waste is any waste (solid or liquid) that is generated in the diagnosis, treatment or immunization of human beings or animals which carries a higher potential for infection and injury than any other type of infection. The important waste generating sources are government and private hospitals, nursing homes, clinics, blood bank, laboratories and research organizations etc. Inadequate and inappropriate handling of health care wastes has serious public health consequences and significant impact on the environment. Inadequate waste management will cause environmental pollution, unpleasant smell, growth and multiplication of vectors and may lead to typhoid cholera, hepatitis and even AIDS. It is estimated that annually about

Now today nursing is considered as a professional discipline that includes the art of applying scientific knowledge to practice. The World Health Organization has classified waste in 8 categories, those are human anatomical waste, blood and body fluids, animal, slaughters house waste, microbiology, biotechnology waste, waste sharps, discarded medicines and solid waste. As per the rule of Bio medical waste - 1998 explains that who generate, dispose biomedical waste in any manner is expected to have proper knowledge, practice and capacity to guide others for waste collection, management and proper handling technique. Effective management of biomedical waste is not only a legal necessity but also a social responsibility. The risk from the health care waste are to staff including medical, paramedical and house maintenance personnel, patients and their attendees, visitors, workers in the laundry, recycling plants transportation, landfills, scavengers and public. Although there is an increased global awareness among health professionals about the hazards and also appropriate management techniques but the level of awareness in Sri lanka is found to be unsatisfactory. Effective management of Biomedical Waste (BMW) is not only a legal necessity but also a socialresponsibility.Adequate knowledge and practice skills about the health hazards of hospital waste as well as laboratory waste, proper techniques and methods of handling the waste and practice of safety measures are needed.

\section{Material and Method}

A descriptive study was conducted to assess the practice of biomedical waste management among staff nurses. Study participants included staff nurses working in different units or wards of the hospital. A total of 60 staff nurses participated in the study and were observed for biomedical waste management practices. An observational checklist was predesigned to observe the practice of the staff nurse. There were 25 dichotomous questioned prepared in the observational checklist. The data was collected by observing the practices of biomedical waste management and each 


\section{International Journal of Science and Research (IJSR) \\ ISSN (Online): 2319-7064 \\ Index Copernicus Value (2013): 6.14 | Impact Factor (2015): 6.391}

correct practices was given a score of „one ${ }^{\text {ee }}$ and wrong practices was given a score of ,zero". Self-made scoring system was used to categorize the participants as whether they follow the correct practice, partially correct practice or the incorrect practice. The score was interpreted as follows: Level of Practice Score of Percentage Correct practices $>75 \%$ Partially correct practices $51-75 \%$ Incorrect practices $<50 \% 3$. Results The findings of the study are discussed in terms of objective and hypothesis of the study. Sample Characteristics Most of the subjects (63.34\%) were in the age group of 21-30 years and minimum numbers of subjects (6.66\%) were found in the age group of 40 years and above. Most of the subjects were female $68 \%$ and male $32 \%$. Most of the subjects $34 \%$ had 5 years and above experiences, $10 \%$ had 1.1-2 years experience, and minimum 18\% had 3 - 4 years experience and $<1$ year experience.

Most of the subjects $36.6 \%$ got information from the colleagues which may be due to comfort approach, 26.6\% got information from mass media which may be due to easy accessibility and also from the supervisors, got and only $10 \%$ from the doctors. With regard to area of working most of the subjects $53.3 \%$ were from the ward area, $23.3 \%$ were from the out patient and clinic area, $13.4 \%$ from operation theatre and the minimum of subjects $10 \%$ were from the casualty area. The objective was to assess the practice of biomedical waste management among staff nurses. The frequency and percentage distribution of level practice on biomedical waste management among staff nurses reveals that $34(56.66 \%)$ had were following correct practices, $14(23.33 \%)$ of staff nurses were following partially correct practices, and 12(20\%) were following incorrect practices. Table 1 shows that $34(56.66 \%)$ of staff nurses were found following the correct practices, 14(23.33\%) were found following partially correct practices and 12(20\%) were found to be following the incorrect practices of biomedical waste management.

Table 1: Level of practices on biomedical waste management among staff nurses

\begin{tabular}{|c|c|c|}
\hline Level of practice $\%$ & No $(n=30)$ & Percentage $\%$ \\
\hline Correct practices & 34 & $56.66 \%$ \\
\hline Partially correct practices & 14 & $23.33 \%$ \\
\hline Incorrect practices & 12 & $20 \%$ \\
\hline
\end{tabular}

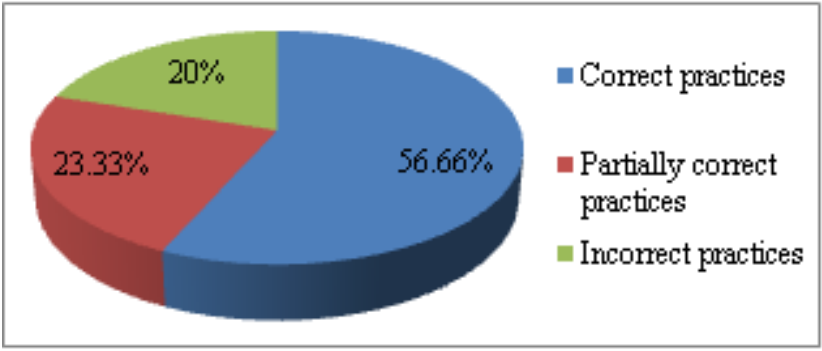

Figure 1: Percentage distribution on level of practices among staff nurses on biomedical waste management

\section{Discussion and Conclusion}

The participants involved in this study were assessed for the practice with regards to biomedical waste management. The study showed that only $56.66 \%$ of the staff nurses were found to be following the correct practices of biomedical waste management. The rest were ignorant on all counts regarding the practice. The implication drawn from the study are of vital concern to all health care team members and need to be incorporated in both theory and practice. The importance of training regarding biomedical waste management cannot be overemphasized; lack of proper and complete knowledge about biomedical waste management impacts practices of appropriate waste disposal. Factors such as increase workload, lack of staff in the wards, less supervision also have a major impact on the practice of biomedical waste management. Thus the following recommendation needs to be implemented: (i) strict implementation of biomedical waste management rules is the need of the hour, supervision of biomedical waste programme in the hospital and its documentation, (ii) conducting the orientation programme for the new staff members and (iii) organizing continuous awareness programme amongst the staff members

\section{References}

[1] Basavanthappa B.T. (2000), "Fundamentals of Nursing", 1st edition, Jaypee Publication, New Delhi, Pp no: $250-255$

[2] Catalono J.T. (1996), "Contemporary Professional Nursing”, F.A Davis Company, Philadelphia, Pp no: 23 $-26$

[3] Denis F.P. Beck, et.al (2002), "Fundamental of Nursing", 1st edition, Jaypee Publication, New Delhi, Pp no: $115-117$

[4] Lalitha D (1993), “ Essentials of community medicine practical approach", 1st edition, New Delhi, Pp no:

[5] J.E Park, (2002), “ Textbook of preventive and social medicine", 17th edition, Minera press, New Delhi, Pp no: $17-22$

[6] Krishnaswamy, (1978), “ Methodology of research in social science"1st edition, Himalaya publishing house, Bombay, Delhi, Pp no: 47,76 - 77

[7] Madhuri S (2000), "Hospital waste management \& its monitoring", 1st edition, Jaypee Publication, New Delhi, Pp no: 113 - 117

[8] Meeta Singh D.B, Acharya, (2002), "The Handbook of Hospital Waste Management", 1st edition, Minera Press, New Delhi, Pp no: 17 - 22

[9] N.C Swaiademy Marie Rose, (1987), "Foundation of Nursing Research", 1st edition, Large Publishers, California, Pp no: 47 - 48

\section{Journals References}

[10] Acharya.D.(2008): study of awareness status about hospital waste management among personnel "Indian journal of public health",vol:47(1).

[11] Ayayoshida, "Journal of material cycle and waste management", Publication - Springer Japan.

[12] CardoseM.R,et.al,(2005), study on biomedical waste management among nurses "BMC public health",Vol:3.

[13] Chen TetKhaun and Alias Abdul-Rahman "Lecture Notes in Geoinformation and Cartography, Innovations in 3D Geo Information Systems.

[14] Clare I. R. (2003), Knowledge and practice related to waste management among doctors, nurses, and housekeepers in the surgical departments, "American Journal Tropical Medical Hygiene" Vol:79(6)

\section{Volume 5 Issue 4, April 2016}




\section{International Journal of Science and Research (IJSR) \\ ISSN (Online): 2319-7064}

Index Copernicus Value (2013): 6.14 | Impact Factor (2015): 6.391

[15]Elsiver, "International Journals of integrated waste management science and technology", Editor - Cossu

[16] "Journal of solid waste technology and management",

Publisher - Widener University, National centre for resource management. 